\title{
Ionic liquids with Dimethyl Phosphate Anion as Highly Efficient Materials for Technological Processes: A Review
}

\author{
Zicmanis $\mathbf{A}^{\star}$ and Zeltkalne $\mathbf{S}$ \\ Faculty of Chemistry, University of Latvia, 19, Raina Blvd, LV-1586, Riga, Latvia
}

\section{Article Info}

*Corresponding author:
Andris Zicmanis
Faculty of Chemistry
University of Latvia
19, Raina Blvd, LV-1586
Riga, Latvia
E-mail: zicmanis@latnet.lv

Received: April 9, 2018

Accepted: April 16, 2018

Published: April 22, 2018

Citation: Zicmanis A, Zeltkalne S. Ionic liquids with Dimethyl Phosphate Anion as Highly Efficient Materials for Technological Processes: A Review. Int I Petrochem Res. 2018; 2(1): 116-125.

doi: 10.18689/ijpr-1000121

Copyright: @ 2018 The Author(s). This work is licensed under a Creative Commons Attribution 4.0 International License, which permits unrestricted use, distribution, and reproduction in any medium, provided the original work is properly cited.

Published by Madridge Publishers

\begin{abstract}
Petrochemistry needs stable, environmentally-friendly and efficient materials for use in the transformation, purification, and analysis of oil products. lonic liquids (ILs) meet these requirements. A novel group of ILs with a very specific anion - dimethyl phosphate (DMP) ion - has appeared recently and can be designated as ILs-DMP. The DMP anion increases hydrophilicity and allocates the complex-formation capacity to ILs-DMP. Although these new materials have been widely used in cellulose dissolution processes, they have not been explored sufficiently in petrochemistry. There is a reason to believe that, in comparison with other ILs, the DMP anion can also provide additional benefits in oil chemistry. Unfortunately, no collected information is available about ILsDMP in literature. The information presented in the review can pave the way to new applications of these unique materials.
\end{abstract}

Keywords: Ionic liquids, Dimethyl phosphate anion, Preparation, Analysis, Applications.

\section{Introduction}

lonic liquids (ILs) have gained a stable position in technology and research in the last quarter of the $20^{\text {th }}$ century. The possibility to adjust their structures to the application needs until the best match is reached is the biggest advantage of ILs in comparison with conventional molecular organic solvents (MOSs). The negligible vapor pressure that removes their volatility, followed by a threat of ignition or poisoning, the great ability to dissolve the most diverse substances, and other features are noted when discussing ILs. Therefore, it does not come as a surprise that ILs are used in various branches of both industry and science, and new applications of ILs appear frequently [1] [2] [3]. To date, more than 240 review articles about ILs have been published. New review papers about some significant areas of their use have already appeared this year, for instance, about the conversion of carbohydrates into value-added small molecules [4], about the thermal, electrochemical and radiolytic stability of ILs [5], about the use of ILs in lithium and sodium batteries [6], for $\mathrm{CO} 2 / \mathrm{CH} 4$ and $\mathrm{H} 2 \mathrm{~S} / \mathrm{CO} 2$ separations [7], and others.

ILs with dialkyl phosphate anions and, most frequently, with the dimethyl phosphate anion (ILs-DMP), can be considered as newcomers in the large family of ILs. Even if they have formally been known for more than a half of century since the first patent in 1951 [8], ILs-DMP attracted the attention of specialists only after the famous publication of the extensive research of the Wasserscheid's group about these materials [9] that have properties noticeably superior to other ILs in almost all indicators. ILs-DMP have different cations that, for the most part, are 1,3-dialkylimidazolium ions. Unquestionably, the greatest asset of 
ILs-DMP is their ability to dissolve cellulose, the most common biopolymer in nature. Investigations of other uses of ILs-DMP started after the highly successful dissolution of cellulose. ILs-DMP form a separate group of ILs, and ILs with other dialkyl phosphate anions are usually included in this group. For all that, no specialized review article is available about ILs-DMP that would critically evaluate the properties of these prospective materials and their possible applications. The present review is intended to contribute to filling this shortage.

\section{Preparation}

Presently, ILs-DMP are prepared using two methods both in industry and in laboratories: by the alkylation of amines (phosphines, nitrogen heterocycles) (Scheme 1) and by the alkylation of the chloride anion in pre-made ILs that have this anion (Scheme 2).

The alkylation of amines, phosphines or nitrogen heterocycles is the first and most widespread type of production of ILs-DMP. Alkylation with trimethyl phosphate is usually carried out by stirring reagents at $80-100{ }^{\circ} \mathrm{C}$ for $24-48 \mathrm{~h}$ under helium, argon or nitrogen [9], with a small molar excess of trimethyl phosphate. Alkylation with other trialkyl phosphates requires more severe conditions. So, reactions between tertiary amines and triethyl phosphate come to an end only at $120^{\circ} \mathrm{C}$ after 24-48 $\mathrm{h}$, while reactions with tributyl phosphate demand a temperature $160{ }^{\circ} \mathrm{C}$ for $72 \mathrm{~h}$ [9]. These alkylation reactions are carried out in aprotic solvents, such as toluene, ethyl acetate, acetonitrile, and others [9] [10]. No unanimous opinion exists among researchers about the best solvent for these reactions. The choice of the solvent used largely depends on the established practice in each specific laboratory. The use of ketones (acetone, 2-butanone) as solvents is undesirable in synthesizing ILs-DMP due to the staining of the products (ILs-DMP) that is very difficult to remove. Even repeated treatment of the stained IL-DMP solutions in the solution of methanol with charcoal does not eliminate the unwanted color. ILs-DMP are remarkably hygroscopic materials. Therefore, their protection from contact with air moisture is indispensable. Some researchers perform the synthesis successfully in tightly closed containers, most frequently in a steel cylinder that allows easier protection of the reaction mixture from contact with air, or use solvents with lower boiling temperatures. Pure ILs-DMP can be obtained when exact reaction conditions are maintained, and only the solvent and its residue should be removed from the reaction mixture after the synthesis. This can be done in different ways, and probably the best procedure is simple rinsing of the product with ethyl acetate for several times, followed by vacuum drying of the purified product. The whole process is time-consuming. Fortunately, the yields of ILs-DMP are high with alkylation ( $\geq 95 \%)$. Notably, if the product is colored yellow or brown, it is always possible to cleanse it by treating its methanol solution with charcoal for several times, until the solution becomes colorless. Needless to say, each purification leads to a decrease in yield. At the same time, the otherwise good method, the alkylation reaction, has a serious limitation: a methyl group is introduced in the IL-DMP cation simultaneously with the formation of the anion. Fortunately, the presence of the methyl group usually is not an obstacle for use of the prepared ILs-DMP. The obtaining of a popular IL-DMP -1-butyl-3-methylimidazolium dimethyl phosphate - is shown below just for illustration (Scheme 1).

$$
\mathrm{C}_{4} \mathrm{H}_{9}-\mathrm{O} N \frac{\mathrm{O}\left(\mathrm{OCH}_{3}\right)_{3}}{\mathrm{CH}_{3} \mathrm{CN} / 80^{\circ} \mathrm{C} / 24 \mathrm{~h} / \mathrm{N}_{2}}{ }_{4} \mathrm{C}_{9}-\mathrm{O}_{3}
$$

Scheme 1. The main preparation method of ILs-DMP (the first route).

According to the second method, ILs-DMP are prepared by alkylation with the trimethyl phosphate of a pre-made salt, which has the chloride anion in its structure, such as ammonium, phosphonium, or nitrogen heterocyclic onium chlorides [11] [12]. In fact, it is the alkylation of the chloride anion. The mixture of the salt and trimethyl phosphate is stirred and heated at 100 $120{ }^{\circ} \mathrm{C}$ for that purpose, the end of the gas (chloromethane) evaluation signaling for the end of the reaction. This anion metathesis reaction greatly increases the diversity of the substances to be obtained and removes the main constraint of the first method, the compulsory introduction of a methyl group in the cations of ILs-DMP, thus expanding the range of available ILs-DMP. The synthesis of 1-butyl-3-octylimidazolium dimethyl phosphate is presented below for the illustration of the method (Scheme 2).

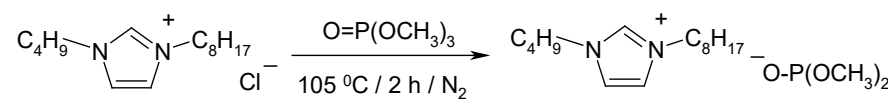

$$
\begin{aligned}
& \text { - } \mathrm{CH}_{3}-\mathrm{Cl}
\end{aligned}
$$

Scheme 2. The alternative preparation method of ILs-DMP (the second route).

\section{Analysis}

Both traditional and quite specific analytical methods are used for the characterization of ILs-DMP. The choice of the analyses mainly depends on the utilization needs of ILs-DMP.

\section{Traditional methods}

The most widely used analytical method of ILs-DMP is the high performance liquid chromatography (HPLC), in a tandem with mass spectrometry. Traditional and highly advanced instruments are used in these analyses, and the method can be considered as both a qualitative and quantitative analytical method. Another required analysis of ILs-DMP is the determination of the moisture content in them using the Karl Fisher titration method, taking into account the high hygroscopicity of these 
materials. Thermogravimetry can be mentioned as the third required analysis of ILs-DMP that limits the temperature interval for the use of these materials. The type of the cation is mainly responsible for the thermal stability of ILs-DMP. Heterocyclic imidazolium DMPs are highly heat-resistant substances that can be heated up to 280-340 ${ }^{\circ} \mathrm{C}$, while aliphatic tetraalkylammonium salts decompose as early as at temperatures starting from $120{ }^{\circ} \mathrm{C}$. Unfortunately, decomposition temperatures of ILs-DMP depend on several factors, including the heating rate, the type of atmosphere, and even the type of an analytical vessel. Therefore, different decomposition temperatures appear in the literature for the same ILDMP. The fourth commonly used analysis of ILs-DMP is the determination of their viscosity. The measurements are highly dependent on the presence of a molecular liquid (other solvent) in ILs-DMP, which most often is water. Viscosities of liquid ILs-DMP cover a wide range on the viscosity scale and depend on the measuring temperature. Viscosity is usually measured only for materials intended for transfer with flow (in tubes, as lubricants, etc.) [1] [2] [9].

\section{Specific methods}

The titrimetric quantitative analysis of ILs-DMP can be deemed the most important specific analytical method. ILsDMP can be easily titrated with perchloric acid in the solution of glacial acetic acid [13] [14]. The DMP anion (pKa 1.29 [15]) reacts with the strong acid, and the titrimetric analysis at the same time allows confirming the purity of the prepared ILDMP. It is worth noting that the obtained titration curves are of high quality, and this allows easy finding of the equivalence point. The content of the basic substance usually is $\geq 99.5 \%$ in carefully synthesized ILs-DMP. The titrimetric analysis can be considered as the most accurate quantitative way of characterization of IL-DMP samples. UV-Vis spectroscopy is also proposed for the same purpose, although it is less popular [16]. The second popular and often used specific method is ${ }^{1} \mathrm{H}$ NMR spectroscopy of ILs-DMP, including the comparison of integral intensities of resonance signals. The integral intensity of six protons of the DMP anion (doublet at $\delta 3.28 \mathrm{ppm}$ ) should correspond to the integral intensities of protons in the cation of the same IL-DMP, for example, to the integral intensities of two protons $\left(\mathrm{C}_{4}-\mathrm{H}\right.$ and $\left.\mathrm{C}_{5}-\mathrm{H}\right)$ in a 1,2,3-trisubstituted imidazolium cation.

The mentioned comparison is particularly important in the case when ILs-DMP are prepared by the alkylation of the chloride ion with trimethyl phosphate (the second route of preparation), as it confirms a complete transformation of the chloride ion. Unfortunately, the analysis of ${ }^{1} \mathrm{H}$ NMR spectra gives much more inaccurate information than the titrimetric analysis. For some ILs-DMP, the polarity is measured using solvatochromic dyes, most frequently Nile Red [17]. They are not "superpolar" solvents regardless of their ionic structure, as their polarity is somewhere between methanol and acetonitrile. There is very little available information about the toxicity of ILs-DMP. The DMP anion makes the biggest contribution to the total toxicity of ILs-DMP [18]. The amphiphilic ILs-DMP also show a marked toxicity on biological cells and liposomes [19]. A specific simple method has been devised for evaluating the toxicity of mixtures of ILs-DMP with other ILs, which is dependent on the mixture information only [20]. The "green" nature of ILs-DMP is called into question after measuring the phytotoxicity of 1-ethyl-3methylimidazolium DMP [21]. Densities of some ILs-DMP are measured mainly for their application in dissolving biomass [22], as well as for understanding the effect of electrostatic interactions on the density of ILs [23]. The physicochemical properties of trialkylphosphonium cation-based ILs-DMP that are less known to the public are described in detail in an extensive research, particularly emphasizing their increased thermal stability [24].

\section{Application}

The excellent dissolution capacity is the most praised property of ILs-DMP, and the light dissolution of cellulose is the best example of it. The high dissolution ability is based on the additional cooperation of the solute with both the cation and the anion (DMP ion) of IL-DMP, in distinction from molecular liquids (water or organic solvents), where such cooperation is impossible. Furthermore, the DMP anion can additionally show some complex-formation interaction with the solute. All these forms of cooperation promote more efficient dissolution of the solutes in ILs-DMP than in other ILs, although the exact dissolution mechanism of ILs-DMP has not been determined yet.

\section{Investigations in petrochemistry}

To date, the use of ILs-DMP in petrochemistry has not been sufficiently investigated, despite the distinct advantages of these materials in comparison with other ILs. The main achievements of applications of some well-known ILs in the upstream oil industry have been collected and analyzed in an excellent recent review [25]. Desulfurization of fuel oil [26] and diesel oil [27] [28] using ILs-DMP should be noted as the most successful application examples. The removal of dimethyl disulfide via extraction using imidazolium-based ILs-DMP has also been very successful, and various extraction parameters have been recognized [29]. The aromaticity indices and double-bond equivalents were studied to seek a simpler approach in identifying the ILs-DMP suitable for the desulphurization processes [30]. A total of 168 possible cation and anion combinations in ILs, including ILs-DMP, were screened with COSMO-RS (Conductor-like Screening Model for Real Solvents) for the purpose of desulphurization of diesel oil, and good agreement was reached between the experimental and calculated data [28]. Asphaltene separation with ILs-DMP was investigated for the deasphaltenes process using a quantum chemical approach and COSMO-RS [31]. Separation of hydrocarbons (crude bitumen, heavy crude oil) from materials containing mineral solids has been highly successful [32]. The activity coefficients were determined at infinitive dilution of alkanes, alkenes, and alkyl benzenes in ILs-DMP using gas-liquid chromatography [33]. ILs-DMP have 
turned out to be superior solvents for the headspace gas chromatography of residual solvents with a very low vapor pressure, the best of them being 1-( $n$-butyl)-3methylimidazolium DMP [34]. There is no doubt that ILs-DMP will find a wide range of applications in all kinds of oil product analyses in the near future.

\section{Dissolution of biopolymers}

The largest number of studies on ILs-DMP are devoted to the dissolution of biopolymers, mainly of cellulose, and these investigation have been very successful [35] [36] [37], including the dissolution of food processing byproducts, such as corncobs [38]. Only a few ILs-DMP are capable to dissolve cellulose efficiently, the best of them being 1-ethyl-3methylimidazolium diethyl phosphate [35]. The anions of ILs capable to dissolve cellulose should be good hydrogen bond acceptors, and DMP is such an anion. It has been established that a cation also plays a significant role in the dissolution process, the imidazolium cation being superior to others [36]. The ionic liquid-pretreated cellulose was transformed into the water-soluble sugar completely [39] [40]. Many attempts have been made to find out the precise mechanism of dissolution [41] [42] [43], thermodynamics of the dissolution processes [44], and the stability of cellulose during the dissolution process [45], as well as the viscosity of high-concentration cellulose solutions in ILs-DMP [46].

Plant fibers were made from IL-DMP solutions, including fibers from the regenerated plant fiber raw material [47], purified cellulose fibers [48], and even lignocellulosic materials [49]. An efficient process for purifying cellulosic materials has been developed [65], which includes the separation and removal of hemicellulose [50] [51]. Enhanced production of sugars and lignin by means the fractionation of lignocellulosic biomass in IL-DMP solutions has been proposed [52]. Recent extensive solubility studies of different sugars in ILs-DMP [53] have facilitated the biopolymer degradation research.

Dissolution possibilities of other biopolymers in ILs-DMP have been studied much less, except for the widespread biopolymer chitin, which has been studied quite thoroughly [54] [55]. It is worth mentioning that the addition of an aprotic diluent (DMSO) has noticeably affected the dissolution process [55]. The possibility of selective dissolution of xylan - the most important type of hemicellulose - has also been described [56]. The authors have also modified the DMP anion by substituting one oxygen atom for sulfur and selenium, respectively. This alteration has reduced the hydrogen bond basicity of the ILs-DMP and has prevented the dissolution of cellulose fibers, whereas the less ordered xylan was still dissolved. The extraction of lignin from lignocellulosic biomass was evaluated with the COSMO-RS method, and the effect of cation and anion combination in ILs-DMP was compared with that in other ILs [57]. Valuable results have been obtained in the experiments of pretreatment of lignocellulosic biomass with ILs-DMP, owing to their ability to disrupt the extensive hydrogen-bonding network. This has facilitated the subsequent enzymatic hydrolysis and improved the sugar yield [58] [59]. Highly successful dissolution of wool keratin in ILs-DMP was reported recently, and fibers obtained from these solutions are used in textile industry and medicine [60] [61]. 1-Butyl-3methylimidazolium DMP was recognized as the best solvent for this purpose. It can completely dissolve $5.0 \mathrm{wt} \%$ wool keratin at $120^{\circ} \mathrm{C}$. Earlier, the protein stability in ILs-DMP was determined using the differential scanning fluorimetry [62]. An efficient method for dissolving peanut meal in ILs-DMP has also been proposed [63], and several methods have been developed for the preparation of peanut protein composite fibers from these solutions [64] [65]. Next, the rheological properties of concentrated gelatin solutions in some ILs-DMP have been examined, and the existence of entanglement coupling between gelatin chains in the solutions has been discovered [66]. An interesting method has also been proposed for the preparation of silkworm fiber material from solutions in ILs-DMP [67].

Further modifications of biopolymers in IL-DMP media have been successful. Esterified cellulose pulp compositions are prepared from available wood pulp sources, and their hemicellulose content is distinct from the cellulose esters prepared by conventional esterification processes [68]. Carboxyl cellulose is prepared by grafting the cellulose material with an acid anhydride in ILs-DMP [69]. A number of succinic acid-based products have been obtained from biomass with ILs-DMP and high-pressure carbon dioxide [70]. A method for the preparation of an enzyme cellulaseimmobilizing carrier from the straw treated with ILs-DMP and a modifier has been proposed. The method produces no pollution, has mild operation conditions and a simple and feasible treatment process, and the IL and modifier can be completely recovered [71]. A method of silylation of lowmolecular-weight carbohydrates (glucose, mannose and lactose) in ILs has been developed for their gas chromatographic analysis, and the derivatization reagents and reaction conditions have been evaluated for different carbohydrates [72]. Ball-milled lignocellulosic biomass was dissolved and acetylated in ILs-DMP with or without a cosolvent in order to find milder dissolution conditions and to mitigate possible degradation processes [73]. Further, a process of lignin oxidation in ILs-DMP coupled with the separation for the production of high added-value aromatic aldehydes has been proposed [74]. A method for the preparation of sodium lignosulfonate from crop straw has been demonstrated [75]. Another useful method relates to the production of regenerated biopolymers in the form of carbohydrates, such as cellulose, starch, et al., using a solvent system that contains ILs-DMP and protic solvents [76]. A highly useful experimental investigation about the pretreatment of sugarcane bagasse with ILs-DMP to facilitate the enzymatic production of bioethanol has been performed [77] (see, section 3.5 below).

\section{Other separations}

Extractions and separations of other products from the main product are less investigated in IL-DMP media. Screening of various ILs for the extraction of pentachlorophenol and 
dichlorodiphenyltrichloroethane from aqueous solutions using the COSMO-RS model for the prediction of the selectivity of these compounds has been reported [78]. A similar approach is used for the prediction of selective extraction of all three cresols [79]. ILs-DMP have proved to be superior extractants than traditional organic solvents for the determination of negligible amounts of phenols [80]. ILsDMP are even considered as novel partitioning media for water purification devices [81]. A simple and green extraction method has been proposed to recover vitamin $E$ from the deodorizer distillate with the help of ILs-DMP, and the theoretical expectations successfully satisfy the experimental results [82]. Recently, ILs-DMP were found to be highly valuable as separation agents for terpenes and terpenoids [83]. Even a high-value triterpenoid betulinic acid can be easily extracted by ILs-DMP after streamlined oxidation of the birch bark industrial byproduct [84]. A quite new application area for ILs-DMP is in extracting polyester from the fabrics that contain polyester and dyes. Unfortunately, no economic considerations are presented in the patent [85]. Finally, the recovery of thiophene from crude benzene by extraction with ILs-DMP has been proposed [86].

\section{Synthetic transformations of organic substances}

Transformations of organic substances have been less investigated in ILs-DMP than in other ILs. The excellent dissolution capacity of ILs-DMP is usually availed of, since it is considerably higher than that of traditional organic solvents, and sometimes their catalytic action appears in these transformations.

The displacement of poisonous chromium catalysts with lanthanide catalysts in the process of the direct conversion of glucose to 5-(hydroxymethyl)furfural has been successful in ILs-DMP [87]. Notably, a higher reactivity was observed in contrast to analogous chromium catalyst systems when the hydrophobicity of the imidazolium cation in an IL-DMP was increased. Further, a base-free conversion of the aromatic aldehyde into 2,5-furandicarboxylic acid was also reported, and the possibility of using non-noble metal catalysts in these oxidations was demonstrated [88]. The aerobic oxidation of 5-(hydroxymethyl)furfural over solid ruthenium hydroxide catalysts in ILs-DMP at elevated temperatures and pressures wasalsoinvestigated. Unfortunately, both 2,5-furandicarboxylic acid and 5-(hydroxymethyl)-2-furancarboxylic acid are formed in these oxidation reactions [89]. Nevertheless, these reactions serve well for the transformation of renewable natural resources (straw, corn stems, etc.) into useful products of fine organic synthesis. The production of glycerol carbonate from glycerol over selected ammonium and imidazoliumbased ILs-DMP was recently reported. The discovery helps solving the problem of unintentional byproduct generation in the biodiesel industry [90]. Another possibility was researched to convert glycerol in IL-DMP media in its reaction with $\mathrm{CO}_{2^{\prime}}$ and it turned out that the "protected glycerol" can serve as a useful and cheap solvent [91]. Ionic liquids themselves represent an alternative solvent system to absorb $\mathrm{CO}_{2}$ from emission sources, demonstrating distinct advantages over traditional solvents (e.g., aminoethanol): high chemical stability, low corrosion, nearly zero vapor pressure, etc. [92] The use of high-stability Rh carbonylation catalysts in the production of acetic acid from methanol in IL-DMP media in rather harsh reaction conditions (at $170-230{ }^{\circ} \mathrm{C}$ and $2.0-4.0$ $\mathrm{MPa}$ ) has been proposed [93]. Catalytic hydrogenation has also been investigated in ILs-DMP over atomically dispersed supported metal catalysts, and the results have demonstrated a wide range of options for adjusting the catalytic properties of the catalysts used [94]. The selective hydrogenation of 1,3-butadiene to cis- or trans-butene from the crude C4 steam cracker fraction represents a convincing example of a selective reaction using a solid catalyst covered with a ionic liquid layer (SCILL) [95]. The behavior of other catalysts copper complexes of acetyl acetone in particular - in ILs-DMP and organic solvents was investigated by the spectroscopic and electrochemical techniques, and the redox behavior of these complexes was described [96]. The interaction between ILs-DMP and acetone was also studied, and acetone was found to be a strong hydrogen bond acceptor in these media [97]. Recently, the gold-catalyzed dimeric cyclization of 1-phenylpropenes into 2,3-dihydro-1H-indenes was examined in ILs-DMP, and the main patterns of these cyclizations were described [98]. Even catalyst compositions for olefin metathesis in a gas phase were described for ILsDMP, and the manufacture of ethene and 1-butene from propene was demonstrated [99]. Sometimes, ILs-DMP have served as reaction media and catalysts at the same time. This double manifestation has been demonstrated for some Knoevenagel condensation reactions [10] [12] and even for the syntheses of heterocyclic compounds, such as 1,4-dihydropyridine derivatives [100]. The syntheses of some polymers in IL-DMP media have also been described: poly(caprolactone) with low polydispersity was prepared by the controlled ring-opening polymerization of $\varepsilon$-caprolactone [101]; piperazine-based polyimides were prepared in ILs with a higher degree of polymerization than in the conventional polymerization processes [102]; poly( $\beta$-alanine) was successfully synthesized in the direct polyamidation reaction of $\beta$-alanine with triphenyl phosphite as the condensing agent [103]; and hybrid-supported metallocene catalysts were successfully tested for polyolefin syntheses using these catalysts [104].

\section{Enzymatic transformations of organic substances}

Despite the well-known instability of enzymes, the enzymatic reactions of organic compounds have been very successfully induced in IL media, including ILs-DMP. The possibility of preparation of isoamyl acetate was demonstrated already 10 years ago using the immobilized enzyme Candida antarctica lipase B and IL-alcohol biphasic system. The recyclability of the IL-enzyme set has been studied extensively, and the system was found to be reusable 7 to 10 cycles [105]. Later on, the activity of several enzymes was studied in different ILs, and the enzymes were found to be most active in ILs-DMP [106]. Sometimes, chemically modified cations of ILs-DMP improve the activity and stability of enzymes, for example, 
formate dehydrogenase in the [mmim][DMP] solution [107] [108]. ILs-DMP have also served as biocompatible solubilizers for hardly water-soluble substances, for example, in the stereoselective reduction of ketones using the alcohol dehydrogenase from Lactobacillus brevis [109]. Interesting and promising are investigations in electroenzymatic syntheses, efforts to combine oxidoreductase-catalyzed reactions with the electrochemical reactant supply [110]. However, the most important is the enzymatic hydrolysis (saccharification) of cellulose in ILs-DMP. Different cellulose-containing materials have been hydrolyzed in ILs-DMP in this way: bagasse [111], chestnut shells [112], barley straw [113], etc. Different methods have been used for the separation of glucose from enzymatic hydrolysis mixtures, mainly alumina column chromatography [114]. A new approach to enzymatic reactions in IL-DMP media is the use of purposefully made model enzymes, for example, the model cellulase from polybasic carboxylic acid, inorganic acid and IL [115], or polybasic carboxylic acid and organic base [116]. It is too early to judge about the development prospects for these approaches. Admittedly, enzymatic transformations are less developed in ILs-DMP than in other ILs.

\section{Use in electrochemistry}

The use of ILs-DMP in electrochemistry is also less developed than in other ILs. The information about the possibilities of such use can be found mainly in patent literature. Printed energy storage devices [117] and printed silver oxide batteries [118] are described in detail. Benefits of ILs-DMP when used as electrolytes for photovoltic devices are praised [119]. These materials are also useful in electric lightcontrolling elements [120]. A great success is the application of ILs-DMP in cyanide-free copper-zinc electroplating liquids, and several recipes have been proposed for non-cyanide plating solutions [121] [122]. ILs-DMP have also served as composite materials for the preparation of very specific electrochromic devices [123]. There is also an innovative method of preparation of a heteroatom in-situ doped carbonbased catalyst for the fuel cell proposed, with flexible and changeable doping species of heteroatoms and high doping efficiency [124].

\section{Other applications}

Applications of ILs-DMP in other areas are still fragmentary. They have been used in high-temperature environmentfriendly lubricant compositions [125]. They have helped to change the interfacial behavior, such as wettability and adhesion of surfaces, and the well-known possibility to design the necessary structure of ILs has been highly useful in developing the very best compositions for concrete surfaces [126]. Absorption heat transformers using ILs-DMP together with water or methanol as working fluids have been proposed, and these systems are superior in comparison with the previous ones [127]. Phase diagram data have been obtained for aqueous two-phase systems containing ILs-DMP and potassium salts [128]. ILs-DMP have been used as entrainers in the azeotropic systems of water/ethanol, water/2-propanol, and water/tetrahydrofuran [129]. Original information has been obtained about the interactions that control the phase behavior of aqueous biphasic systems composed of poly (ethylene glycol) polymers and ILs-DMP. The adjustable structural features of ILs and the influence of the molecular weight of the PEG polymer have been discussed [130]. Recently, the use of eutectic mixtures of ILs-DMP as absorbents in absorption chillers was proposed [131]. The addition of ILsDMP to polymer compositions has delayed crystallization and lowered the crystallization point of thermoplastic polymers [132]. ILs-DMP have helped in producing porous structures from synthetic polymers (fibers, sheets, films, coatings, etc.) [133]. Liquid layers of ILs-DMP have alleviated the stress generated between the substrate and the solid ultra-thin film, and the flexibility of films [134] and chemical-mechanical properties of tribofilms have been studied in depth [135]. Recently, ILs-DMP have helped to accomplish a rather difficult task: the fabrication of polyethersulfone flat sheet membranes. The obtained membrane morphologies were compared with those of the membranes prepared from solutions in DMF and were further successfully applied in DNA separations [136].

No matter how diverse the available information about ILs-DMP is today, more is yet to come. There is no doubt that there will be more pleasant surprises for researchers of these materials in the near future.

\section{Conclusions}

ILs-DMP are readily available materials with chemical and mechanical properties superior to most other ILs. Safe and reliable methods have been developed for their qualitative and quantitative analyses. Just the first attempts are made in using these materials in oil chemistry. Their use is much better explored in the dissolution of cellulose and related materials, although there is still no credible explanation for their increased dissolution capacity. The dissolution of other biopolymers in ILs-DMP has also been quite successfully developed, as well as different transformations of biopolymers. Other areas of use are represented only with some examples. Of course, future developments in these areas are open. At the same time, the influence of the structure of ILs-DMP on the processes performed in their media has not been sufficiently appreciated by now. The number of dialkyl phosphate anions is limited. This makes it difficult to appreciate the true impact of the anion in the examined processes. Investigations in these directions might lead to a considerable selectivity increase of ILs-DMP in different application processes.

\section{Acknowlwdgement}

The authors sincerely acknowledge the material and financial support of the University of Latvia.

\section{References}

1. Wasserscheid $P$, Welton T. Ionic Liquids in Synthesis. Weinheim: WileyVCH. 2008; 1-174. doi: 10.1002/9783527621194

2. Hallett JP, Welton T. Room-Temperature Ionic Liquids: Solvents for Synthesis and Catalysis. 2. Chem Rev. 2011; 111(5): 3508-3576. doi: $10.1021 / \mathrm{cr} 1003248$ 
3. Olivier-Bourbigou H, Magna L, Morvan D. Ionic liquids and catalysis: recent progress from knowledge to applications. Appl Catal A. 2010; 373(1-2): 1-56. doi: 10.1016/j.apcata.2009.10.008

4. Bodachivskyi I, Kuzhiumparambil U, Williams DBG. Acid-Catalyzed Conversion of Carbohydrates into Value-Added Small Molecules in Aqueous Media and lonic Liquids. ChemSusChem. 2018; 11(4): 642-660. doi: 10.1002/cssc.201702016

5. Xue Z, Qin L, Jiang J, et al. Thermal, electrochemical and radiolytic stability of ionic liquids. Phys Chem Chem Phys. 2018; 20(13): 8382-8402. doi: 10.1039/C7CP07483B

6. Yang $Q$, Zhang $Z$, Sun $X G$, et al. lonic liquids and derived materials for lithium and sodium batteries. Chem Soc Rev. 2018; 47(6): 2020-2064. doi: 10.1039/C7CS00464H

7. Wang $\mathrm{LY}, \mathrm{Xu} \mathrm{YL}$, $\mathrm{Li} \mathrm{ZD}$, et al. $\mathrm{CO}_{2} / \mathrm{CH}_{4}$ and $\mathrm{H}_{2} \mathrm{~S} / \mathrm{CO}_{2}$ Selectivity by lonic Liquids in Natural Gas Sweetening. Energy Fuels. 2018; 32(1): 10-23. doi: 10.1021/acs.energyfuels.7b02852

8. Werntz JH. Quarternary ammonium salts of phosphorus acid esters. USA Patent 2,563,506, 1951

9. Kuhlmann E, Himmler S, Giebelhaus H, Wasserscheid P. Imidazolium dialkylphosphates - a class of versatile, halogen-free and hydrolytically stable ionic liquids. Green Chem. 2007; 9: 233-242. doi: 10.1039/B611974C

10. Priede $E$, Brica $S$, Udris N, Zicmanis A. Designing highly efficient solvents for the Knoevenagel condensation: two novel dicationic dimethyl phosphate ionic liquids. ARKIVOC. 2015; (7): 243-252. doi: 10.3998/ ark.5550190.p009.355

11. Yu PD, Boydston JA, Bielawski CW. lonic liquids via efficient, solvent-free anion metathesis. Green Chem. 2007; 9: 1158-1159. doi: 10.1039/ b705745h

12. Priede $E$, Bakis $E$, Zicmanis $A$. When chlorides are the most reactive: a simple route towards diverse mono- and dicationic dimethyl phosphate ionicliquids.Synlett. 2014;25(17):2447-2450. doi:10.1055/s-0034-1379018

13. Chen $X$, Song $H$, Chen $P$, et al. Studying of the basicity of ionic liquids by potentiometric titration. Acta Chim Sinica. 2012; 70(6): 770-774. doi: 10.6023/A1108223

14. Zicmanis A, Anteina L. Dialkylimidazolium dimethyl phosphates as solvents and catalysts for the Knoevenagel condensation reaction. Tetrahedron Lett. 2014; 55: 2027-2028. doi: 10.1016/j.tetlet.2014.02.035

15. Kumler WD, Eiler JJ. The Acid Strength of Mono and Diesters of Phosphoric Acid. The n-Alkyl Esters from Methyl to Butyl, the Esters of Biological Importance, and the Natural Guanidine Phosphoric Acids. J Am Chem Soc. 1943; 65(12): 2366-2361. doi: 10.1021/ja01252a028

16. Xu JX, Li YM, Li YM, Hou Y. Determination of the purity of [Mmim]DMP ionic liquidnrapidly by utilizing ultraviolet spectrophotometry. Zhongguo Zaozhi. 2014; 33(12): 33-37.

17. Paterno A, D'Anna F, Fortuna CG, Musumarra G. Polarity study of ionic liquids with the solvatochromic dye Nile Red: a QSPR approach using in silico VolSurf + descriptors. Tetrahedron. 2016; 72(23): 3282-3287. doi: 10.1016/j.tet.2016.04.056

18. Biczak R, Pawlowska B, Balczewski P, Rychter P. The role of the anion in the toxicity of imidazolium ionic liquids. J Hazard Mater. 2014; 274: 181-190. doi: 10.1016/j.jhazmat.2014.03.021

19. Mikkola SK, Robciuc A, Lokajova J, et al. Impact of Amphiphilic BiomassDissolving lonic Liquids on Biological Cells and Liposomes. Environ Sci Technol. 2015; 49(3): 1870-1878. doi: 10.1021/es505725g

20. Zhang J, Liu SS, Liu HL, et al. A novel method dependent only on the mixture information (MIM) for evaluating the toxicity of mixture. Environ Pollut. 2011; 159(7): 1941-1947. doi: 10.1016/j.envpol.2011.03.018

21. Biczak R, Balczewski P, Pawlowska B, Rychter P. Phytotoxicity of ionic liquid, a derivative of imidazole. Proceedings of ECOpole. 2012; 6(1): 183-191.

22. Mac Dowell $N$, Llovell $F$, Sun $N$, et al. New experimental density data and soft-SAFT models of alkylimidazolium $([\mathrm{C}(\mathrm{n}) \mathrm{C} 1 \mathrm{im}]+)$ chloride $(\mathrm{Cl}-)_{\text {, }}$ methylsulfate ([MeSO4]-), and dimethylphosphate ([Me2PO4]-) based ionic liquids. J Phys ChemB. 2014; 118(23): 6206-6221. doi: 10.1021/jp501619y
23. Wang J, Li C, Shen C, Wang Z. Towards understanding the effect of electrostatic interactions on the density of ionic liquids. Fluid Phase Equilibria. 2009; 279(2): 87-91. doi: 10.1016/j.fluid.2009.02.011

24. Yoshi K, Yamaji K, Tsuda T, et al. Physicochemical Properties of Tri-nbutylalkylphosphonium Cation-Based Room-Temperature lonic Liquids. J Phys Chem B. 2013; 117(48): 15051-15059. doi: 10.1021/jp406791a

25. Sulemana NT, Ghosh B. Application of lonic Liquids in the Upstream oil Industry-A Review. Int J Petrochem Res. 2017; 1(1): 50-60.

26. Gao $S$, Chen X, Abro R, et al. Desulfuriztion of Fuel Oil: Conductor-like Screening Model for Real Solvents Study on Capacity of lonic Liquids for Thiophene and Dibenzothiophene. Ind Eng Chem Res. 2015; 54(38): 9421 9430. doi: 10.1021/acs.iecr.5b01385

27. Anantharaj R, Benerjee T. Fast Solvent Screening for the Simultaneous Hydrodesulfurization and Hydrodenitrification of Diesel Oil Using lonic Liquids. J Chem Eng Data. 2011; 56(6): 2770-2785. doi: 10.1021/je1011289

28. Anantharaj R, Banerjee T. COSMO-RS based predictions for the desulphurization of diesel oil using ionic liquids: Effect of cation and anion combination. Fuel Process Technol. 2011; 92(1): 39-52. doi: 10.1016/j. fuproc.2010.08.018

29. Tian Y, Meng X, Shi L. Removal of dimethyl disulfide via extraction using imidazolium-based phosphoric ionic liquids. Fuel. 2014; 129(1): 225-230. doi: 10.1016/j.fuel.2014.03.019

30. Abdullah SB, Man Z, Bustam MA. Investigation of aromaticity index and double bond equivalent of aromatic compounds and ionic liquids for fuel desulphurization. J Chem. 2013; 838590: 7. doi: 10.1155/2013/838590

31. Rashid Z, Wilfred CD, Murugesan T. Asphaltene Separation with Designer Solvents for the Deasphaltenes Process-A Quantum Chemical Approach. Procedia Engineering. 2016; 148: 268-274. doi: 10.1016/j. proeng.2016.06.562

32. Kyllonen L, King A, Kiljunen S, Hesampour M. Method for separating hydrocarbons and use of molten salt. PCT Int Appl. WO 2015193550 A1 20151223, 2015.

33. Ge ML, Lu CY, Liu XY, et al. Activity coefficients at infinitive dilution of alkanes, alkenes, alkyl benzenes in dimethyl phosphate based ionic liquids using gas-liquid chromatography. J Chem Thermodin. 2015; 91: 279-285. doi: 10.1016/j.jct.2015.07.046

34. Laus $G$, Andre $M$, Bentivoglio $G$, Schottenberger $H$. Ionic liquids as superior solvents for headspace gas chromatography of residual solvents with very low vapor pressure, relevant for pharmaceutical final dosage forms. J Chromatogr A. 2009; 1216(32): 6020-6023. doi: 10.1016/j. chroma.2009.06.036

35. Vitz J, Erdmenger T, Haensch C, Schubert US. Extended dissolution studies of cellulose in imidazolium based ionic liquids. Green Chem. 2009; 11(3): 417-424. doi: 10.1039/B818061J

36. Lall-Ramnarine SI, Thomas MF, Jalees MP, et al. Probing the Physical Properties, Synthesis and Cellulose Dissolution Ability of Dialkyl Phosphate Ionic Liquids. Phosphorus, Sulfur and Silicon and the Related Elements. 2015; 190(5-6): 891-895. doi: 10.1080/10426507.2014.985824

37. Vitz J, Erdmenger T, Schubert US. Imidazolium based ionic liquids as solvents for cellulose chemistry. ACS Symp Ser. 2010; 1033: 299-317. doi: 10.1021/bk-2010-1033.ch017

38. Zhang $X, N i e Y$, Zhang $S$, et al. Method for preparing corncob cellulose solution or fiber material with ionic liquid. Faming Zhuanli Shenqing. CN 104004207 A 20140827, 2014.

39. Wu W, Liu W. Process for transforming ionic liquid-pretreated cellulose into water-soluble sugar completely. Faming Zhuanli Shenqing. CN 102796143 A 20121128, 2012.

40. Liu W, Hou Y, Wu W, et al. Complete conversion of cellulose to water soluble substances by pretreatment with ionic liquids. Korean J Chem Eng. 2012; 29(10): 1403-1408. doi: 10.1007/s11814-012-0023-2

41. Rabideau BD, Agarwal A, Ismail AE. Observed Mechanism for the Breakup of Small Bundles of Cellulose $\alpha \alpha$ and $\beta \beta$ in lonic Liquids from Molecular Dynamics Stimulations. J Phys Chem B. 2013; 117(13): 3469-3479. doi: 10.1021/jp310225t 
42. Nunes de Oliveira HF, Rinaldi R. Understanding Cellulose Dissolution: Energetics of Interactions of Ionic Liquids and Cellobiose Revealed by Solution Microcalorimetry. ChemSusChem. 2015; 8(9): 1577-1584. doi: 10.1002/cssc.201500272

43. Rabideau BD, Ismail AE. Mechanism of hydrogen bond formation between ionic liquids and cellulose and the influence of water content. Phys Chem Chem Phys. 2015; 17(8): 5767-5775. doi: 10.1039/C4CP04060K

44. Parviainen $H$, Parviainen $A$, Virtanen $T$, et al. Dissolution enthalpies of cellulose in ionic liquids. Carbohydr Polym. 2014; 113: 67-76. doi: 10.1016/j.carbpol.2014.07.001

45. Clough MT, Griffith JA, Kuzmina O, Welton T. Enhancing the stability of ionic liquid media for cellulose processing: acetal protection or carbene suppression? Green Chem. 2016; 18(13): 3758-3766. doi: 10.1039/ C6GC00027D

46. Jarvi $P$, Granstroem M, King AWT, et al. Study of viscosity of cellulose ionic liquid solutions at high concentrations. Annual Transactions - Nordic Rheology Society. 2011; 19: 339-343.

47. Chen J, Zhang Z, Pang Z, Yang G. Method for improving regenerated plant fiber raw material performance. Faming Zhuanli Shenqing. CN 103882763 A 20140625, 2014.

48. Okumura A, Kumar KA, Sugimoto K, Koide K. Manufacture of purified cellulose fibers capable of effectively recycling ionic liquid solvents. Jpn Kokai Tokkyo Koho. JP 2014019716 A 20140203, 2014.

49. Kipelainen I, King A, Karhunen P, Matikainen J. Process for fibrillating lignocellulosic materials using ionic liquids. PCT Int Appl. WO 2011114004 A1 20110922, 2011.

50. Fallon $D$, Garrett $T$, Kizer $L E$, et al. Processes for purifying a cellulosic material. PCT Int Appl. WO 2014179673 A1 20141106, 2014.

51. Li R, Mehta J, Tu X, et al. Methods for removing hemicellulose from cellulose materials. PCT Int Appl. WO 2014031672 A2 20140227, 2014.

52. Paripati $P$, Dadi AP. Enhanced production of sugars and lignin via fractionation of lignocellulosic biomass through ionic liquid pretreatment and mild alkaline treatment. PCT Int Appl. WO 2014144588 A1 20140918, 2014.

53. Mohan M, Goud VV, Banerjee T. Solubility of glucose, xylose, fructose and galactose in ionic liquids: Experimental and theoretical studies using continuum solvation model. Fluid Phase Equilib. 2015; 395: 33-43. doi: 10.1016/j.fluid.2015.03.020

54. Wang WT, Zhu J, Wang $\mathrm{XL}$, et al. Dissolution Behavior of Chitin in lonic Liquids.JMacromolSciB.2010;49(3):528-541.doi:10.1080/00222341003595634

55. Bochek AM, Murav'ev AA, Novoselov NP, et al. Specific features of cellulose and chitin dissolution in ionic liquids of varied structure and the structural organization of regenerated polysaccharides. Russ J Appl Chem. 2012; 85(11): 1718-1725. doi: 10.1134/S1070427212110158

56. Froschauer $C$, Hummel $M$, Laus $G$, et al. Dialkyl phosphate-related ionic liquids as selective solvents for xylan. Biomacromolecules. 2012; 13(6): 1973-1980. doi: 10.1021/bm300582s

57. Balaji C, Banerjee T, Goud VV. COSMO-RS Based Predictions for the Extraction of Lignin from Lignocellulosic Biomass Using lonic Liquids: Effect of Cation and Anion Combination. J Solution Chem. 2012; 41(9): 1610-1630. doi: 10.1007/s10953-012-9887-3

58. Sengupta A, Zabala A, Tan SY, et al. Characterization of an ionic liquidtolerant $\beta$-xylosidase from a marine-derived fungal endophyte. Biochem Cell Biology. 2017; 95(5): 585-591. doi: 10.1139/bcb-2017-0053

59. Xie H, Zhao Z, Yu X. Pre-treatment method of lignocellulosic biomass for improving its sugar yield. Faming Zhuanli Shenqing. CN 105385722 A 20160309, 2016.

60. Wang L, Nie Y, Zhang X, et al. Synergistic Effects of Cosolvents on the Dissolution of Wool Keratin Using lonic Liquids. Chem Eng Tech. 2016; 39(5): 979-986. doi: 10.1002/ceat.201500646

61. Nie $Y$, Zhang $S$, Zhang $X$, et al. Preparation method of ionic liquid keratin spinning solution. Faming Zhuanli Shenging. CN 103710775 A 20140409, 2014.
62. Rodrigues JV, Prosinecki V, Marrucho I, et al. Protein stability in an ionic liquid milieu: on the use of differential scanning fluorimetry. Phys Chem Chem Phys. 2011; 13(30): 13614-13616. doi: 10.1039/C1CP21187K

63. Sun J, Yang $Q, Y u$ S, et al. Method for dissolving peanut meal using imidazolium ionic liquid. Faming Zhuanli Shenqing. CN 102326803 A 20120125, 2012.

64. Sun J, Jie $Y$, Zhang $C$, et al. Method for preparing peanut protein-collagen blended composite fiber. Faming Zhuanli Shenqing. CN 104264274 A 20150107, 2015.

65. Sun J, Yang Q, Yu L, et al. Method for preparing peanut protein composite fibers using ionic liquid. Faming Zhuanli Shenqing. CN 102586942 A 20120718, 2012

66. Horinaka Jl, Okamoto A, Takigawa T. Rheological properties of concentrated solutions of gelatin in an ionic liquid 1-ethyl-3methylimidazolium dimethyl phosphate. Int J Biol Macromolecules. 2016; 91: 789-793. doi: 10.1016/j.ijbiomac.2016.06.032

67. Li $\mathrm{Q}, \mathrm{Ji} \mathrm{G}$, Zhang $\mathrm{D}$, et al. Method for preparing silkworm fiber material. Faming Zhuanli Shenqing. CN 105200558 A 20151230, 2015.

68. Luo $M$, Dodd A, West $H$, et al. Esterified cellulose pulp compositions and related making esterified cellulose pulp and injection molded articles from the esterified cellulose pulp. US Pat Appl. US 20150376836 A1 20151231, 2015.

69. Zhang $D$, Li Q, Ji G, et al. Method for preparing carboxyl cellulose by grafting cellulose material with acid anhydride in ionic liquid. Faming Zhuanli Shenqing. CN 105461815 A 20160406, 2016.

70. Silva D, Bogel-Lukasik E. Valuable new platform chemicals obtained by valorization of a model succinic acid and bio-succinic acid with an ionic liquid and high-pressure carbon dioxide. Green Chem. 2017; 19(17): 40484060. doi: $10.1039 / C 7 G C 00952 F$

71. Li Q, Ji G, Li B, et al. Method for preparing cellulase-immobilizing carrier from straw treated by ionic liquid and modifier. Faming Zhuanli Shenqing. CN 103667243 A 20140326, 2014.

72. Ruiz-Aceituno L, Carrero-Carralero C, Ramos L, et al. Development of a carbohydrate silylation method in ionic liquids for their gas chromatographic analysis. Anal Chim Acta. 2013; 787: 87-92. doi: 10.1016/j.aca.2013.05.042

73. Qu C, Kishimoto T, Hamada M, Nakajima N. Dissolution and acetylation of ball-milled lignocellulosic biomass in ionic liquids at room temperature: application to nuclear magnetic resonance analysis of cell-wall components. Holzforschung. 2013; 67(1): 25-32. doi: 10.1515/hf-20120037

74. Liu S, Shi Z, Li L, et al. Process of lignin oxidation in an ionic liquid coupled with separation. RSC Advances. 2013; 3(17): 5789-5793. doi: 10.1039/ C3RA40391B

75. Wu D. Method for preparing sodium lignosulfonate from crop straw. Faming Zhuanli Shenqing. CN 105885058 A 20160824, 2016.

76. Uerdingen $E$, Siemer $N$, Lutz $M$, et al. Method for producing regenerated biopolymers and regenerated products obtained by said method. PCT Int Appl. WO 2009062723 A1 20090522, 2009.

77. Bahrani S, Raeissi S, Sarshar M. Experimental investigation of ionic liquid pretreatment of sugarcane bagasse with 1,3-dimethylimidazolium dimethyl phosphate. Bioresource Technol. 2015; 185: 411-415. doi: 10.1016/j.biortech.2015.02.085

78. Pili SR, Banerjee T, Mohanty K. Extraction of pentachlorophenol and dichlorodiphenyltrichloroethane from aqueous solutions using ionic liquids. J Ind Eng Chem. 2012; 18(6): 1983-1986. doi: 10.1016/j. jiec.2012.05.017

79. Kumar L, Banerjee T, Mohanty K. Prediction of Selective Extraction of Cresols from Aqueous Solutions by lonic Liquids Using Theoretical Approach. Sep Sci Technol. 2011; 46(13): 2075-2087. doi: 10.1080/01496395.2011.589421

80. Mohanty S, Banerjee T, Mohanty K. Quantum Chemical Based Screening of Ionic Liquids for the Extraction of Phenol from Aqueous Solution. Ind Eng Chem Res. 2010; 49(6): 2916-2925. doi: 10.1021/ie901684q 
81. Boda A, Ali SM, Shenoi MR, et al. lonic liquid as a novel partitioning media. Desalination and Water Treatment. 2012; 38(1-3): 323-331. doi: 10.1080/19443994.2012.664393

82. Qin L, Zhang J, Cheng $H$, et al. Selection of Imidazolium-Based lonic Liquids for Vitamin Extraction from Deodorizer Distillate. ACS Sustainable Chem Eng. 2016; 4(2): 583-590. doi: 10.1021/acssuschemeng.5b01330

83. Martins MAR, Domanska U, Schroder B, et al. Selection of lonic Liquids to be used as Separation Agents for Terpenes and Terpenoids. ACS Sustainable Chem Eng. 2016; 4(2): 548-556. doi: 10.1021/ acssuschemeng.5b01357

84. Ressmann AK, Kremsmayr T, Gaertner $P$, et al. Toward a benign strategy for manufacturing of betulinic acid. Green Chem. 2017; 19(4): 1014-1022. doi: 10.1039/C6GC02641A

85. Walker A. Recycling process comprising extracting polyester from fabric comprising polyester and one or more dyes using solvent system. Brit UK Pat Appl. GB 2528494 A 20160127, 2016.

86. Hu $Y$, Wang $G$, Zeng $D$, et al. Recovery of thiophene in simulative crude benzene by extraction with ionic liquid. Huaxue Gongcheng. 2011; 39(8): $65-68$.

87. Stahlberg $T$, Sorensen MG, Riisager A. Direct conversion of glucose to 5-(hydroxymethyl)furfural in ionic liquids with lanthanide catalysts. Green Chem. 2010; 12(2): 321-325. doi: 10.1039/B916354A

88. Yan $D$, Xin J, Shi C, et al. Base-free conversion of 5-hydroxymethylfurfural to 2,5-furandicarboxylic acid in ionic liquids. Chem Eng J. 2017; 323: 473482. doi: 10.1016/j.cej.2017.04.021

89. Stahlberg T, Eyjolfsdottir E, Gorbanev YY, et al. Aerobic Oxidation of 5-(Hydroxymethyl)furfural in lonic Liquids with Solid Ruthenium Hydroxide Catalysts. Catal Lett. 2012; 142(9): 1089-1097. doi: 10.1007/ s10562-012-0858-5

90. Ishak ZI, Sairi NA, Alias Y, et al. Production of glycerol carbonate with aid of ionic liquid as catalyst. Chem Eng J. 2016; 297: 128-138. doi: 10.1016/j. cej.2016.03.104

91. Melo Cl, Rodrigues Al, Bogel-Lukasik R, Bogel-Lukasik E. Outlook on the Phase Equilibria of the Innovative System of "Protected Glycerol": 1,4-Dioxaspiro[4,5]decane-2-methanol and Alternative Solvents. J Phys Chem A. 2012; 116(7) 1765-1773. doi: 10.1021/jp2107796

92. Maiti A. Theoretical Screening for Ionic Liquid Solvents for Carbon Capture. ChemSusChem. 2009; 2(7): 628-631. doi: 10.1002/cssc.200900086

93. Jiang $X, L i C$. High stability carbonylation catalyst for production of acetic acid, and its application method. CN Patent. CN 101716527 A 20100602 , 2010.

94. Babucci M, Fang $\mathrm{CH}$, Hoffman AS, et al. Tuning the Selectivity of SingleSite Supported Metal Catalysts with lonic Liquids. ACS Catalysis. 2017; 7(10): 6969-6972. doi: 10.1021/acscatal.7b02429

95. Mangartz $T$, Korth $W$, Kern C, Jess A. Selective hydrogenation of 1,3-butadiene from crude C4 cracker stream with a Solid Catalyst with Ionic Liquid Layer (SCILL)-DSC and solubility study. DGMK Tagungsbericht. 2013; 243-248.

96. Nunes $P$, Nagy MV, Alegria ECBA, et al. The solvation of redox behavior of mixed ligand copper(II) complexes of acetylacetonate and aromatic diimines in ionic liquids. Inorg Chim Acta. 2014; 409(PB): 465-471. doi: 10.1016/j.ica.2013.09.040

97. Ruiz E, Ferro VR, Palomar J, et al. Interaction of lonic Liquids and Acetone: Thermodynamic Properties, Quantum-Chemical Calculations, and NMR Analysis.J J Phys Chem B. 2013; 117(24): 7388-7398. doi: 10.1021/jp402331y

98. Morita N, Mashiko R, Hakuta D, et al. Gold-Catalyzed Dimeric Cyclization of Isoeugenol and Related 1-Phenylpropenes in Ionic Liquid: Environmentally Friendly and Stereoselective Synthesis of 1,2,3-Trisubstituted 2,3-Dihydro-1H-indenes. Synthesis. 2016; 48(12): 1927-1933. doi: 10.1055/s-0035-1561604

99. Szesni N, Mueller S, Fischer R, et al. Use of catalyst composition for olefin metathesis in the gas phase and procedure for the olefin metathesis in the gas phase. Ger Offen. DE 102009017498 A1 20101028, 2010.
100. Priede E, Zicmanis A. One-Pot Three-Component Synthesis of Hantzsch 1,4-Dihydropyridines Promoted by Dimethyl Phosphate lonic Liquids. Helv Chim Acta. 2015; 98(8): 1095-1103. doi: 10.1002/hlca.201500009

101. Oshimura M, Takasu A, Nagata K. Controlled Ring-Opening Polymerization of $\varepsilon$-Caprolactone Using Polymer-Supported Scandium Trifluoromethanesulfonate in Organic Solvent and lonic Liquids. Macromolecules. 2009; 42(8): 30863091. doi: 10.1021/ma802870n

102. Alici B, Koytepe $S$, Seckin T. Synthesis of piperazine based polyimide in the presence of ionic liquids. Turkish J Chem. 2007; 31(6): 569-578.

103. Zhang S, Dias Goncalves L, Lefebvre $H$, et al. Direct Poly( $\beta$-alanine) Synthesis via Polycondensation in lonic Liquids. ACS Macro Lett. 2012; 1(8): 1079-1082. doi: $10.1021 / \mathrm{mz} 300264 \mathrm{v}$

104. Lee HS, Shin DC, Chae SS, et al. Hybrid supported metallocene catalyst, preparing the catalyst, and process for preparing polyolefin using the hybrid catalyst. PCT Int Appl.WO 2013133595 A1 20130912, 2013.

105. Feher E, Illeova V, Kelemen-Horvath I, et al. Enzymatic production of isoamyl acetate in an ionic liquid-alcohol biphasic system. J Mol Catal B: Enzym. 2008; 50(1): 28-32. doi: 10.1016/j.molcatb.2007.09.019

106. Thomas MF, Li LL, Handley-Pendleton JM, et al. Enzyme activity in dialkyl phosphate ionic liquids. Bioresource Technol. 2011; 102(24): 11200-11203. doi: 10.1016/j.biortech.2011.09.069

107. Bekhouche M, Doumeche B, Blum L. Chemical modification by ionic liquid-inspired cations improve the activity and the stability of formate dehydrogenase in [MMlm][Me2PO4]. J Mol Catal B: Enzym. 2010; 65(1-4): 73-78. doi: 10.1016/j.molcatb.2010.01.028

108. Carter JLL, Bekhouche M, Noiriel A, et al. Directed evolution of a formate dehydrogenase for increased tolerance to ionic liquids reveals a new site for increasing the stability. Chembiochem: Eur J Chem Biol. 2014; 15(18): 2710-2718. doi: 10.1002/cbic.201402501

109. Kohlmann $C$, Robertz $N$, Leuchs $S$, et al. Ionic liquid facilitates biocatalytic conversion of hardly water-soluble ketones. J Mol Catal B: Enzym. 2011; 68(2): 147-153. doi: 10.1016/j.molcatb.2010.10.003

110. Kohlmann C, Greiner L, Leitner W, et al. Ionic Liquids as Performance Additives for Electroenzymatic Syntheses. Chem-Eur J. 2009; 15(43): 11692-11700. doi: 10.1002/chem.200901046

111. He $Y$, Gong $L$, Zhang $Y$, et al. Ionic liquid resistant Galactomyces sp. CCZU11-1 and for in situ saccharification of bagasse with cellulase. Faming Zhuanli Shenqing. CN 103013840 A 20130403, 2013.

112. He YC, Liu F, Gong L, et al. Enzymatic in situ saccharification of chestnut shell with high ionic liquid-tolerant cellulases from Galactomyces sp. CCZU11-1 in a biocompatible ionic liquid-cellulase media. Bioresource Technol. 2016; 201: 133-139. doi: 10.1016/j.biortech.2015.11.034

113. Mood SH, Golfeshan AH, Ardjmand M, et al. Comparison of different ionic liquids pretreatment for barley straw enzymatic saccharification. J Biotech 2013; 3(5): 399-406. doi: 10.1007/s13205-013-0157-x

114. Feng D, Li L, Yang F, et al. Separation of ionic liquid [Mmim][DMP] and glucose from enzymatic hydrolysis mixture of cellulose using alumina column chromatography. Appl Microbiol Biotechnol. 2011; 91(2): 399-405. doi: 10.1007/s00253-011-3263-x

115. Li Q, Ji G, Li T, et al. Preparation of model cellulase from polybasic carboxylic acid, inorganic acid and ionic liquid. CN Patent. CN 104437629 A 20150325, 2015

116. Li Q, Ji G, Li T, et al. Preparation of model cellulase using polybasic carboxylic acid ionic liquid formed by reacting polybasic carboxylic acid with organic base and cellulose-solubilizing ionic liquid. CN Patent. CN 104437630 A 20150325, 2015.

117. Lockett VN, Daneshi L, Ray WJ, Gustafson JG. Printed energy storage device. US Pat Appl. US 2014302373 A1 20141009, 2014.

118. Lockett V, Gustafson J, Ray WJ, Salah Y. Printed silver oxide batteries. PCT Int Appl. WO 2015009867 A1 20150122, 2015.

119. Villarroya-Lidon $S$, Chittibabu KG. Electrolyte and photovoltaic cell comprising the same. Brit UK Pat Appl. GB 2518837 A 20150408, 2015. 
120. Nakano M, Hatano K, Ono S, et al. Electric light-controlling element for IR transmittance control of VO2-based material. Jpn Kokai Tokkyo Koho. JP 2013028473 A 20130207, 2013.

121. Feng Z, Feng Y. Cyanide-free copper-zinc electroplating liquid containing ionic liquid. Faming Zhuanli Shenqing. CN 105483778 A 201660413, 2016.

122. Feng Z, Feng Y. Plating method of ionic liquid-containing cyanide-free plating solution of copper and zinc. Faming Zhuanli Shenqing. CN 105463535 A 20160406, 2016.

123. Zhang $X$, Zhang Y, Zhang W, Liu G. Electrochromic composite material for preparation of electrochromic device. Faming Zhuanli Shenqing. CN 105838350 A 20160810, 2016.

124. Gao J, Tian J, Tang L. Preparation method of heteroatom in-situ doped carbon-based catalyst for fuel cell. Faming Zhuanli Shenqing. CN 107146893 A 20170908, 2017.

125. Kong N, Zhu Y, Huang J, et al. High-temperature environment-friendly water-based ionic liquid lubricant. Faming Zhuanli Shenqing. CN 106635360 A 20170510, 2017.

126. Pereira MM, Kurnia KA, Sousa FL, et al. Contact angles and wettability of ionic liquids on polar and non-polar surfaces. Phys Chem Chem Phys. 2015; 17(47): 31653-31661. doi: 10.1039/c5cp05873b

127. Chen W, Liang S. Thermodynamic analysis of absorption heat transformers using [mmim]DMP/H2O and [mmim]DMP CH3OH as working fluids. Appl ThermalEng. 2016;99:846-856. doi:10.1016/j.applthermaleng.2016.01.135

128. Wang L, Zhu H, Ma C, et al. Measurement and Correlation of Phase Diagram Data for Aqueous Two-Phase Systems Containing 1-Ethyl-3methylimidazolium Dimethyl Phosphate + K3PO4/K2HPO4/K2CO3 + H2O lonic Liquids at $(298.15,308.15,318.15)$ K. J Chem Eng Data. 2012; 57(3): 681-687. doi: 10.1021/je2004758
129. Verma VK, Banerjee T. Ionic liquids as entrainers for water + ethanol, water + 2-propanol, and water + THF systems: A quantum chemical approach. J Chem Thermodyn. 2010; 42(7): 909-919. doi: 10.1016/j. jct.2010.03.001

130. Freire MG, Pereira JFB, Francisco M, et al. Insight into the Interactions That Control the Phase Behavior of New Aqueous Biphasic Systems Composed of Polyethylene Glycol Polymers and Ionic Liquids. Chem-Eur J. 2012; 18(6): 1831-1839. doi: 10.1002/chem.201101780

131. Mehrkesh A, Maat $S$, Tamas G. Absorption chiller using eutectic mixture of ionic liquids as absorbent. PCT Int Appl. WO 2017205807 A1 20171130, 2017.

132. Groos B, Pfaendner R. Polymer composition with delayed crystallization, additive and method for lowering crystallization point of thermoplastic polymer. Ger Offen. DE 102015211632 A1 20161229, 2016.

133. Schwiegk S, Wilms A, Lange RFM, et al. Method for producing porous structures from synthetic polymers. PCT Int Appl. WO 2009101111 A1 20090820, 2009.

134. Min YS, Lee WH. Composite thin film having liquid layer for suppressing interfacial stress, flexible device comprising thereof and manufacturing method of the same. Repub Korean Kongkae Taeho Kongbo. KR 2016023601 A 20160303, 2016.

135. Sharma V, Doerr N, Aswath PB. Chemical-mechanical properties of tribofilms and their relationship to ionic liquid chemistry. RSC Advances. 2016; 6(27): 22341-22356. doi: 10.1039/C6RA01915C

136. Kim DL, Vovusha H, Schwingenschlogl U, Nunes SP. Polyethersulfone flat sheet and hollow fiber membranes from solutions in ionic liquids. J Membr Sci. 2017; 539: 161-171. doi: 10.1016/j.memsci.2017.06.001 